\title{
Interstimulus interval and startle response habituation with a "control" for total time during training*
}

\author{
MICHAEL DAVIS $\dagger$ \\ Yale University, New Haven, Conn. (06519)
}

Three groups of rats were exposed to either 1,000 tones at a $2-\sec$ or a 16-sec ISI or 8,000 tones at a $2-\mathrm{sec}$ ISI. Following this, all Ss were given a test session involving presentation of various tone intensities at a $1-\mathrm{min}$ ISI. Test-session performance revealed that, despite the fact that 8,000 tones produced more habituation than 1,000 tones at a $2-\mathrm{sec}$ ISI, 1,000 tones at a 16-sec ISI still produced the most habjtuation. This result could not be attributed to a difference in the time spent in the experimental situation prior to testing and lends strong support to the conclusion that habituation may be greater the longer the ISI during training.

Recently (Davis, in press) it was reported that startle responsiveness was lower following training sessions in which the interval between tone exposures was long rather than short. In that experiment, rats were presented with 1,000 tones either at a 16-sec interstimulus interval (ISI) or a 2-sec ISI. One minute or $24 \mathrm{~h}$ following these training sessions, a test session was administered in which all Ss received identical treatments involving the presentation of 75 tones at each of four different ISIs $(2,4,8$, and $16 \mathrm{sec})$. It was found that during these test sessions startle responsiveness was lower, at each test interval, for Ss that had had a 16-sec as compared to a 2-sec ISI during training. These results suggest, therefore, that when separate training and testing procedures are arranged, habituation, as measured by test session performance, may be greater the longer the ISI has been during training.

A potential problem in comparisons of different ISIs is that the total time in the experimental situation is necessarily confounded with interval length. Thus, in the above experiment, the 16-sec Ss spent eight times as long in the experimental chamber prior to testing as did the 2-sec Ss (about $4 \mathrm{~h}$ vs $1 / 2 \mathrm{~h}$ ). Since it has been reported that repeated daily exposures to an experimental chamber (about $3 \frac{1}{2} \mathrm{~h}$ in total) in the absence of any startle-eliciting stimuli appears to reduce subsequent startle tendency (Korn \& Moyer, 1966), it is possible that the greater time spent in the chamber prior to testing might account for the lower startle level of the 16-sec Ss during testing.

\footnotetext{
*This research was supported by USPHS Grants MH-13917 and MH-07114-10.

$\dagger$ Reprint requests should be sent to Michael Davis, Yale University School of Medicine, Department of Psychiatry, 34 Park Street, New Haven, Conn. 06519.
}

In order to evaluate this possibility, it would be desirable to compare startle tendency following training at a 16 -sec or a 2 -sec ISI in which the total time spent in the experimental situation prior to testing was the same for both groups. One way to do this would be to present an equal number of tones under each condition but to allow Ss in the 2-sec condition to remain in the situation for an additional amount of time: equal to the difference in time required to present, say, 1,000 tones at a 16-sec ISI minus that required to present 1,000 tones at a $2-\sec$ ISI (about $3 \frac{1}{2} \mathrm{~h}$ ).

There is, however, no obvious way in which to distribute the $1 / 2 \mathrm{~h}$ of tone presentation and the $31 / 2 \mathrm{~h}$ of added time over the total 4-h period in the 2 -sec condition. Thus, tone exposure could be given at the beginning, end, or in the middle of the 4-h session. In comparison to the 16-sec ISI condition, however, these procedures would vary either with respect to the interval between the end of tone exposure and the test session, or the beginning of tone exposure and the test session, or both, making none perfectly acceptable.

On the other hand, there is one condition that would seem to be the most powerful control condition, in which Ss would be presented with tones at a $2-\mathrm{sec}$ ISI throughout the entire 4-h session. This would mean, of course, that Ss in this condition would be exposed to eight times as many tones in comparison to the $16-\mathrm{sec}$ Ss. Since it is generally the case that habituation is directly related to the number of stimulations, this difference alone would serve to reduce the possibility of finding greater habituation following the $16-\mathrm{sec}$ condition. If, however, the Ss that received 8,000 tone exposures at a $2-\mathrm{sec}$ ISI were still less habituated than the Ss that received only 1,000 exposures at a 16 -sec ISI, this would provide strong support to the conclusion that habituation may be greater the longer the ISI during training and demonstrate that under these circumstances this effect could not be attributed to different times in the experimental situation, since this would be equivalent for both conditions.

\section{METHOD}

The Ss were 72 male albino rats of the Sprague-Dawley strain, selected to weigh between $350-400 \mathrm{~g}$.

Six stabilimeter devices, which have been described elsewhere (Davis \& Wagner, 1968), were housed in one corner of an $8 \times 8 \times 7 \mathrm{ft}$ sound-attenuated chamber (Industrial Acoustics Company) and were used to measure the occurrence of the startle response. A 15-in. Altec high-frequency loud-speaker was located 45 in. from each of the six stabilimeters and was employed to provide presentation of a $4,000-\mathrm{Hz} 50-\mathrm{msec}$ tone at various ISIs and intensities, according to the experimental plan. The intensity of the tone was measured with a General Radio Model 1551-C sound level meter with a scale setting of $20 \mathrm{kHz}$, by placing the microphone within each of the six cages and positioning the cages to give comparable decibel readings in each. A constant white-noise background of $60 \mathrm{~dB}$ was maintained throughout all phases of the experiment.

On the first experimental day (prehabituation session), each of 18 Ss was placed in a stabilimeter and after $5 \mathrm{~min}$ Ss were presented with nine exposures to each of three tone intensities $(100,110$, and $120 \mathrm{~dB}$ ). The ISI, which will be defined throughout as the time between successive tone onsets, was $1 \mathrm{~min}$. The several intensities were presented in an irregular order, with the restrictions that each intensity followed itself and every other intensity equally often and that the occurrence of each intensity was distributed approximately uniformly over the total sequence of 27 tone presentations. Following this, Ss were returned to their home cages.

The number of startle responses recorded in this prehabituation session was then employed to assign the $18 \mathrm{Ss}$ to three groups of six Ss each, the three groups having similar means and variances at each of the three tone intensities. One of the three matched groups was randomly assigned to each of three experimental treatments, and the six Ss were run concurrently in the six stabilimeters.

On the second experimental day, the Ss were placed in the stabilimeters and after 5 min received 1,000 tone exposures either at a 2-sec ISI (Group 2-1000) or a 16-sec ISI (Group 16-1000) or 8,000 exposures at a 2-sec ISI (Group 2-8000). This will be 


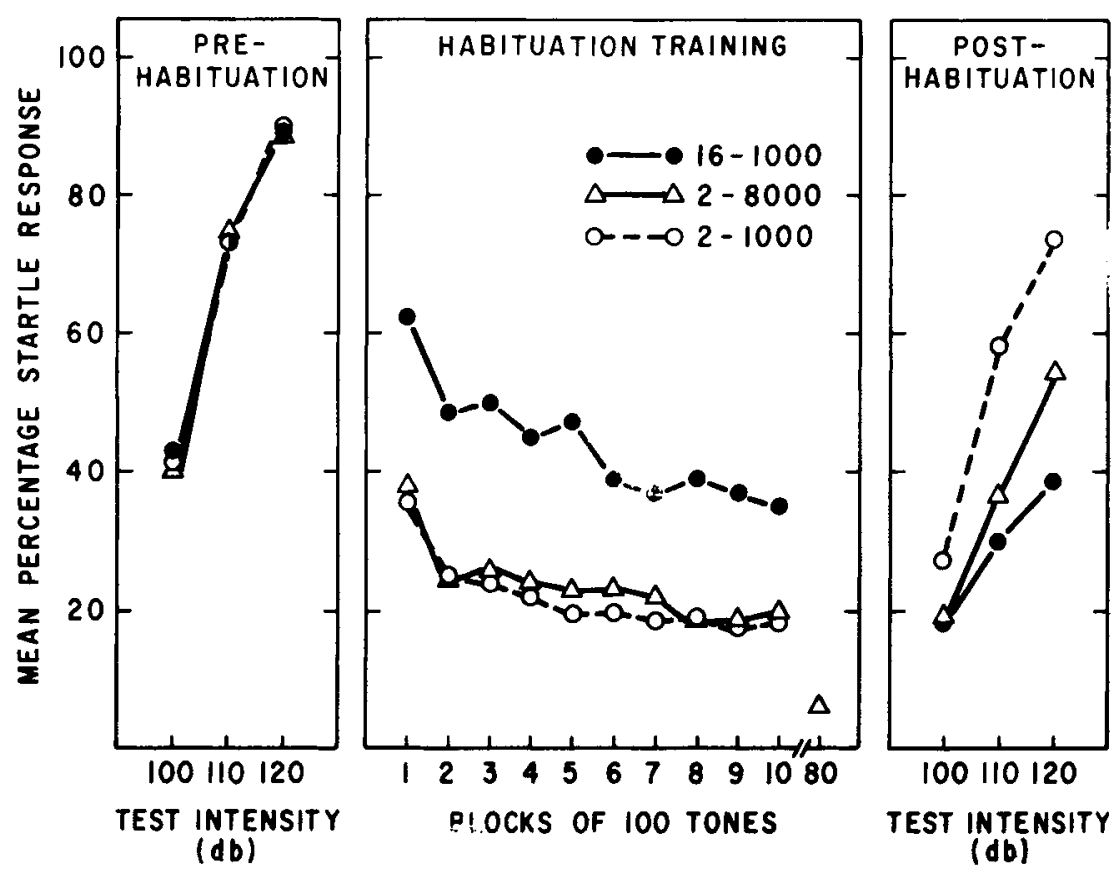

referred to as the habituation training session. The intensity of the tone was $120 \mathrm{~dB}$ for each of the three groups.

Five minutes following the selected habituation treatment, each group was again presented with nine exposures to each of the three tone intensities, at a 1-min ISI, identical to the prehabituation session. The Ss remained in the stabilimeters during this 5-min period.

Four separate replications of the above procedures were conducted, creating a total of 24 Ss in each treatment group. The replications were identical in all respects except that the order in which the three groups were run on the second experimental day was varied, so that the average interval between the pre- and post-habituation sessions, over all replications, was about $24 \mathrm{~h}$ for each group.

\section{RESULTS AND DISCUSSION}

Figure 1 shows the mean percentage startle response combined over all replications for Groups 16-1000, 2-1000, and 2-8000 at each of the three test intensities prior to (left panel) and following (right panel) habituation training. The performance of the various groups over the 10 blocks of 100 tones during the habituation training session is also shown (middle panel). In addition, the performance of Group 2-8000 during its 80 th block of 100 tones is shown as a single point at the end of the habituation training session.

During the prehabituation session, there was a highly reliable overall increase in startle fraquency with increasing intensities of tone $(F=168.66, \mathrm{df}=2 / 138, \mathrm{p}<.001)$.

During the habituation training session, each of the three groups showed a reliable decrease ( $p<.001$, in each case) in startle frequency over the 10 blocks of 100 tones. Group 2-8000 showed a further decrease over the last 7,000 tone presentations, so that it had a lower startle level during Block 80 as compared to Block 10 , as shown in Fig. $1 \quad(t=3.05, \quad d f=23$, $p<.01$ ).

Most apparent during this session, however, was the fact that Group 16-1000 had a much higher startle frequency at each of the 10 blocks of 100 tones as compared to Groups $2-1000$ and $2-8000$ $(t=5.81, d f=46, p<.001$ and $t=3.63$, $\mathrm{df}=46, \mathrm{p}<.001$, respectively). Such comparisons involved, however, evaluation of habituation differences in which the parameters of stimulus exposure differ for different Ss. Since these kinds of comparisons alone have been shown to lead to potentially misleading conclusions, both with respect to the effects of different stimulus intensities (Davis \& Wagner, 1968) and different ISIs (Davis, in press), it is necessary to turn now to the posthabituation session, where the parameters of stimulus exposure were identical for all Ss, in order to assess the amount of habituation that the various treatments may have produced.

Figure 1 shows that each group showed a decrease in startle frequency from the pre- to the posthabituation session ( $\mathrm{p}<.005$, in all cases), indicating that habituation had occurred.

Most important, however, was the fact that startle responsiveness during the posthabituation session was different for the three groups, so that Group 16-1000 was least responsive, Group 2-1000 was
Fig. 1. Mean percentage startle response at each of three tone intensities prior to and following habituation training and over blocks of 100 tones during habituation training for each of the three groups.

most responsive, and Group $2-8000$ had an intermediate level of startle responsiveness. An overall analysis of variance of the posthabituation scores revealed a reliable difference among the groups $(\mathrm{F}=11.44$, $\mathrm{df}=2 / 68, \mathrm{p}<.001)$, a reliable increase in startle with increasing test intensity $(F=75.90, \mathrm{df}=2 / 138, \mathrm{p}<.001)$ and $\mathrm{a}$ reliable Test Intensity by Habituation Treatments interaction $(F=3.98$, $\mathrm{df}=4 / 138, \mathrm{p}<.005)$.

In view of this interaction, subsequent $t$ tests were performed between pairs of groups at each of the three test intensities. No reliable differences were found between any of the groups when the test intensity was $100 \mathrm{~dB}$. However, the lower startle level of Group 16-1000 in comparison to Group 2-1000 was reliable both when the test intensity was $110 \mathrm{~dB} \quad(\mathrm{t}=4.47$, $\mathrm{df}=46, \mathrm{p}<.001)$ and $120 \mathrm{~dB}(\mathrm{t}=6.08$, $\mathrm{df}=46, \mathrm{p}<.001)$. This confirms and extends the previous finding of greater habituation following training on long rather than short ISIs, although it is this difference that could be attributable to different times in the experimental chamber prior to testing.

The lower startle level of Group 2-8000 in comparison to Group 2-1000 was reliable both at $110 \mathrm{~dB}(\mathrm{t}=3.33, \mathrm{df}=46$, $\mathrm{p}<.005)$ and $120 \mathrm{~dB}(\mathrm{t}=4.09$, df $=46$, $\mathrm{p}<.001$ ). This indicated that the 7,000 additional training exposures given to Group 2.8000 were effective in producing more habituation.

Most important for the present context, however, was the comparison between Groups $16-1000$ and $2-8000$. This revealed that the lower startle frequency of Group 16-1000 was not reliable when the test intensity was $110 \mathrm{~dB}(\mathrm{t}=.38, \mathrm{df}=46$, $\mathrm{p}>.10)$ but was at $120 \mathrm{~dB} \quad(\mathrm{t}=2.75$, $\mathrm{df}=46, \mathrm{p}<.01)$. Since the intensity of the tone during training was, in fact, $120 \mathrm{~dB}$, the difference between these groups at this test intensity stresses the potency of the effect of greater habituation following training on longer ISIs. That is, despite the fact that 8,000 tone exposures at a $2-\sec$ ISI were effective in producing more habituation than 1,000 exposures at a 2-sec ISI, this was still not as effective as only 1,000 exposures at a 16-sec ISI, and the difference between Groups 16-1000 and 2-8000 cannot be accounted for in terms of different times in the experimental situation, since this was identical for both groups.

The present results also indicate that the total number of responses made during the 
habituation training session was not a reliable index of subsequent startle tendency. This is important, because it could be argued that the lower startle level of Group 16-1000 in comparison to Group 2-1000 could have been due to some fatigue-like effect, since Group 16-1000 gave so many more responses than Group 2-1000 during training $(\bar{X}=451$ vs 184$)$. Comparison of Groups $16-1000$ and 2.8000 revealed, however, that Group 2-8000 gave many more responses over its entire training session than Group $16.1000(\bar{X}=976$ vs $451, \mathrm{t}=4.07, \mathrm{df}=46, \mathrm{p}<.001$ ) yet still was less habituated at the $120-\mathrm{dB}$ test intensity. While it is possible that a more critical factor might be the number of responses made just prior to testing (e.g., during the last 100 tones during training), which was obviously greater for Group 16-1000 than for Group 2-8000 (Fig. 1), this same comparison could not account for the difference between Groups $2-8000$ and 2.1000, since Group 2-8000 had fewer startles immediately prior to testing, yet was more habituated. It would appear, therefore, that there was no simple relationship between either the total number of responses made during training or the number of responses given immediately prior to testing and degree of habituation, thus making a fatigue interpretation difficult.

In an effort to explain the greater habituation following training on long rather than short ISIs, it has been suggested that this may be a result of differences in the degree to which stimuli are allowed to "consolidate" during training (Davis, in press). Another possibility might be to assume that the different degrees of habituation reflected a difference in the perceived intensity of the tones during training. Thus, it might be the case that the shorter the interval between two tone exposures the lower will be the perceived intensity or loudness of the second. This would suggest, therefore, that the average loudness of the tones during training was less for the 2-sec than for the 16-sec Ss. Since it has been shown (Davis \& Wagner, 1968) that the less intense a tone has been during training the less habituation it will produce as measured during a subsequent test session, prediction based on an intensity interpretation of the ISI effect would be consistent with previous data. Moreover, this line of reasoning would suggest that the ISI effect is simply a special case of a more fundamental intensity effect.

\section{REFERENCES}

DAVIS, M. Effects of interstimulus interval length and variability on startle response habituation in the rat. Journal of Comparative \& Physiological Psychology, in press.

DAVIS, M., \& WAGNER, A. R. Startle responsiveness after habituation to different intensities of tone. Psychonomic Science, $1968,12,337-338$.

KORN, J. H., \& MOYER, K. E. Habituation of the startle response and of heart rate in the rat. Canadian Journal of Psychology, 1966, 20, 183-190.

\title{
The relationship of nonprotein nitrogen and total nitrogen in rat brain to avoidance-extinction behavior
}

\author{
MARTIN GOLD, MORTON H. KLEBAN, HENRY ALTSCHULER, \\ M. POWELL LAWTON, and MARK MILLER
}

Gerontological Research Institute, Philadelphia Geriatric Center, Philadelphia, Pa. 19141

Equal, independent groups of young and aged albino rats were divided among avoidance-plus-extinction, avoidance, and nontraining conditions. Estimates of brain nonprotein nitrogen (NPN) were calculated from protein and total nitrogen values. Significant differences in NPN were found for the three brain sections. The aged animals had higher concentrations of NPN than the young in the avoidance-plus-extinction training condition. These values were significantly correlated with extinction behavior in the aged but not in the young Ss.

Our laboratory has been engaged in studies of the neurochemical changes occurring during avoidance behavior. In a previous paper, estimates of nonprotein nitrogen (NPN) were made from protein and total nitrogen quantities analyzed from the supernatant prepared from total brain tissue. In this report NPN values were calculated for cerebral, brain stem, and cerebellar sections. Both young (Kleban, Gold, Altschuler, Lawton, \& Miller ${ }^{1}$ ) and aged (Altschuler, Lawton, Kleban, Gold, \&
Miller, 1970) rats were investigated to determine if aging caused any difference in response. Chemical analyses were performed on total material in each of the three brain sections.

\section{METHOD}

The experimental apparatus was a 30-in.-long automated straight runway maze. By the rotation of end boxes, acting alternately as start- and goalboxes, around a stationary stem, animals could receive aversive training without handling between trials. It was a massed training procedure, the time between any two trials being 16 sec. The Es will supply a detailed description of the apparatus and the methodology upon request.

The Ss were 72 albino Wistar rats. There were 36 young (60-75 days old) and 36 aged $(\geqslant 24$ months old) rats. By random assignment, the young and aged rats were placed into three experimental conditions: (1) avoidance training; (2) avoidance plus extinction training; and (3) no training (controls). The avoidance group received limited avoidance training for 20 consecutive trials. In limited avoidance training, electric shock (1.0-mA intensity) was experienced on each trial, but the animal could avoid it by action on a section of the grid. After the 20 shock trials, the animals were placed into the experimental cages for $2 \mathrm{~h}$ before being sacrificed by decapitation. In the avoidance-plus-extinction group, after the 20 limited avoidance trials, the rats were given a maximum of 40 extinction trials. Extinction was defined as remaining on the grid for $60 \mathrm{sec}$. Thus, rats could have extinction scores ranging from 1 to 40 trials. These rats were also returned to their experimental cages for $2 \mathrm{~h}$ before decapitation. Control Ss were placed in experimental cages and housed for $2 \mathrm{~h}$ in the experimental room before being decapitated.

The experiment was conducted first on the young rats (Kleban et al, 1970). Chemical analyses were conducted on the brains of single animals. The brains were divided into cerebral, brain stem, and cerebellar sections. The chemical constituents analyzed were RNA, protein, and total nitrogen from the total brain tissue of each section. The experiment was then replicated on aged rats (Altschuler et al, 1970).

The animals were killed by decapitation with a Harvard guillotine and the three brain sections were isolated and homogenized individually for chemical analysis. Protein was analyzed using the procedure of Lowry (1951) and the total nitrogen was assayed by the micro-Kjeldahl method (Koch \& McMeekin, 1924). Commercial RNA and Versatol were used 